\title{
Components in Plasma-Derived Factor VIII, But Not in Recombinant Factor VIII Downregulate Anti-Inflammatory Surface Marker CD163 in Human Macrophages through Release of CXCL4 (Platelet Factor 4)
}

\author{
Anne Bertling ${ }^{a} \quad$ Martin F. Brodde ${ }^{a, b} \quad$ Mayken Visser ${ }^{a} \quad$ Janina Treffon $^{a} \quad$ Michelle Fennen $^{a}$ \\ Anke C. Fender ${ }^{c}$ Reinhard Kelsch ${ }^{d}$ Beate E. Kehrel ${ }^{a}$ \\ ${ }^{a}$ Department of Anesthesiology, Intensive Care and Pain Medicine, Experimental and Clinical Hemostasis, University of Münster, \\ Münster, Germany; \\ bOxProtect $\mathrm{GmbH}$, Münster, Germany; \\ ${ }^{c}$ Institute of Pharmacology and Clinical Pharmacology, Heinrich-Heine-University, Düsseldorf, Germany; \\ d Institute of Transfusion Medicine and Transplantation Immunology, University Hospital Münster, Münster, Germany
}

\section{Keywords}

Hemophilia A · Factor VIII · Platelets - Macrophages ·

Scavenger receptors

\section{Summary}

Background: Hemarthrosis, or bleeding into the joints, is a hallmark of hemophilia. Heme triggers oxidative stress, inflammation, and destruction of cartilage and bone. The haptoglobin-CD163-heme oxygenase-1 (HO1) pathway circumvents heme toxicity through enzymatic degradation of heme and transcription of antioxidant genes. Plasma-derived factor concentrates contain many proteins that might impact on cellular pathways in joints, blood, and vessels. Methods: Activation of platelets from healthy volunteers was assessed by flow cytometry analysis of fibrinogen binding and CD62P expression. Platelet CXCL4 release was measured by ELISA. Human peripheral blood mononuclear cells were exposed to CXCL4 or platelet supernatants (untreated or pre-stimulated with factor VIII (FVIII) products) during their differentiation to macrophages and analyzed for CD163 expression. Some macrophage cultures were additionally incubated with autologous hemoglobin for $18 \mathrm{~h}$ for analysis of HO-1 expression. Results: Platelet CXCL4 release was increased by all 8 tested plasma-derived FVIII products but not the 3 recombinant products. Macrophages exposed to supernatant from platelets treated with some plasma-derived
FVIII products downregulated CD163 surface expression and failed to upregulate the athero- and joint protective enzyme $\mathrm{HO}-1$ in response to hemoglobin. Conclusion: Plasma-derived FVIII products might promote bleeding-induced joint injury via generation of macrophages that are unable to counteract redox stress.

(c) 2017 S. Karger GmbH, Freiburg

\section{Introduction}

Hemophilia A (HA) is an inherited bleeding disorder caused by factor VIII (FVIII) deficiency. Patients with severe HA suffer from recurrent bleeding episodes, with $85 \%$ of the bleeds occurring in the joints [1]. Recurrent joint bleeds cause joint destruction by inducing synovitis, cartilage destruction, and bone damage. Once the joint has been damaged, little can be done to restore anatomic integrity. FVIII concentrate replacement therapy has dramatically improved quality of life for patients with HA by reducing bleeding episodes and resultant joint destruction. However, in spite of early prophylactic treatment, intra-articular hemorrhages and subsequent joint damage cannot be prevented completely [2]. Whenever blood enters the joint space, hemoglobin is released into the plasma. The hemoglobin-derived heme has multiple proinflamma-

\section{KARGER}

() 2017 S. Karger GmbH, Freiburg 
tory effects [3]. In the vicinity of joint cells, iron-containing heme from red blood cells promotes the formation of hydroxyl radicals by the Fenton reaction. In accordance with this, local synovial iron deposits are associated with increased catabolic activities in hemophilia [4]. Careful observation of patient material supplemented with data from animal models of joint disease clearly showed that the major mechanism of hemoglobin-induced joint injury is the deposition of iron in superficial and subsynovial layers of the joint, which is a hallmark of hemophilic synovitis [5]. Iron increases proliferation of synovial cells in a concentration-dependent manner and induces upregulation of mouse double minute 2 homolog (Mdm2) gene [6]. In normal cells, the Mdm2 binds to the tumor suppressor protein $\mathrm{p} 53$ and prevents its function $[7,8]$. Therefore, $M d m 2$ overexpression was proposed to be a suitable target in treating the underlying cell proliferation that leads to synovitis and arthropathy in hemophilia [5].

In blood plasma, hemoglobin released by erythrocytes is immediately captured by the protective acute-phase protein haptoglobin. By forming stable, irreversible complexes with free hemoglobin, haptoglobin inhibits the oxidative activity of hemoglobin and hence protects tissues and cells from hemoglobin-induced damage $[9,10]$. In humans, haptoglobin mediates rapid clearance of hemoglobin through high-affinity binding to the macrophage scavenger receptor CD163 [11]. By mediating the endocytosis of hemoglobinhaptoglobin complexes, CD163 counters hemoglobin-induced oxidative damage after hemolysis [12]. Binding of hemoglobin-haptoglobin complexes to CD163-bearing cells elicits potent interleukin-10 (IL-10) secretion. IL-10 release in turn induces synthesis of the stress protein heme oxygenase-1 (HO-1) via an autocrine mechanism $[13,14]$. HO-1 subsequently decreases inducible hemedependent enzymes, such as inducible nitride oxide synthase (iNOS), cyclooxygenase 2 (COX-2), and NADPH-oxidase, and dampens inflammation. In addition, HO-1 drives ferritin synthesis, leading to increased iron sequestration and loss of its inflammatory properties [15].

CXCL4 is a platelet-derived chemokine that promotes macrophage differentiation from monocytes [16, 17]. Recently, Gleissner et al. $[18,19]$ demonstrated near complete absence of the hemoglobin scavenger receptor CD163 in CXCL4-induced 'M4macrophages.' CD163 mRNA was downregulated within $2 \mathrm{~h}$ of CXCL4 treatment, and CD163 protein reached its expression minimum after 3 days. Supernatant from activated human platelets also reduced CD163 expression by macrophages. CXCL4-differentiated M4-macrophages were unable to upregulate $\mathrm{HO}-1$ at the RNA and protein levels in response to hemoglobin-haptoglobin complexes and failed to endocytose these complexes [18, 19].

Previously, we identified up to $0.85 \mathrm{ng} / \mathrm{IU}$ of the platelet alpha granule protein CXCL4 as well as platelet-activating substances such as myeloperoxidase and alpha-defensin [20] in some plasmaderived FVIII concentrates [21]. Therefore, we tested the direct effect of FVIII products on differentiation of human macrophages. In addition, we studied whether FVIII concentrates might induce CXCL4 release from human platelets and thereby influence macrophage CD163 expression indirectly.

\section{Material and Methods}

\section{Materials}

The conjugation of highly purified human fibrinogen (Enzyme Research Laboratories, South Bend, IN, USA) with fluorescein isothiocyanate (FITC) via FITC-celite (Sigma-Aldrich, St Louis, MO, USA) was performed according to the method of Xia et al. [22] with modifications described by Lahav et al. [23]. The following FVIII concentrates were used in this study: Kogenate ${ }^{\circledR}$ Bayer (Bayer Pharma AG, Berlin, Germany), ReFacto AF ${ }^{\circledR}$ (Pfizer Pharma GmbH, Germany), Advate ${ }^{\circledR}$ and Immunate STIM plus ${ }^{\circledR}$ (Baxter Deutschland GmbH, Unterschleißheim, Germany), Beriate ${ }^{\circledR}$ and Haemate HS ${ }^{\circledR}$ (CSL Behring, Marburg, Germany), Faktor VIII SDH Intersero ${ }^{\circledR}$ (Intersero GmbH, Walluf, Germany), Fandhi ${ }^{\circledR}$ (Grifols, Barcelona, Spain), Haemoctin SDH ${ }^{\circledR}$ (Biotest AG, Dreieich, Germany), and Wilate ${ }^{\circledR}$ and Octanate ${ }^{\circledR}$ (Octapharma GmbH, Langenfeld, Germany).

\section{Preparation of Platelets}

Blood was obtained from the Department of Transfusion Medicine (Münster, Germany) with informed consent from healthy volunteers, who had not taken any medication affecting platelet function for at least 2 weeks before the study. Venous blood drawn from the antecubital vein was anticoagulated with trisodium citrate $(0.0108 \mathrm{~mol} / \mathrm{l})$ and processed within $1 \mathrm{~h}$ after collection to prevent loss of platelet function. Platelet-rich plasma was prepared by differential centrifugation at $200 \times g$ for $10 \mathrm{~min}$ at room temperature. For some experiments, platelets were gel-filtered on Sephadex CL-2B (GE Healthcare, Munich, Germany) as previously described [24]. Platelet supernatant was generated by incubating $1 \times 10^{8}$ gel-filtered platelets for $1 \mathrm{~h}$ with or without (negative control) $2 \mathrm{U} / \mathrm{ml}$ FVIII or with $1 \mu \mathrm{mol} / \mathrm{l}$ adenosine diphosphate (ADP; Boehringer Mannheim, Mannheim, Germany) plus $0.5 \mu \mathrm{mol} / \mathrm{l}$ U46619 (Sigma Aldrich, positive control) in the presence of $3 \mu \mathrm{mol} / \mathrm{l}$ melagatran, a direct thrombin inhibitor. Afterward, platelets were separated from cell-poor supernatant by centrifugation, and cell-free supernatant was obtained by ultracentrifugation (Beckman Coulter, Krefeld, Germany).

\section{Monocyte-Derived Macrophages}

Human peripheral blood mononuclear cells (PBMCs) were isolated from buffy coats (German Red Cross, Münster, Germany) by Biocoll (Biochrom AG, Berlin, Germany) density gradient centrifugation. Simultaneously, the plasma layer above the PBMCs was collected, incubated at $56^{\circ} \mathrm{C}$ for $30 \mathrm{~min}$, and centrifuged at $3,200 \times g$ for $5 \mathrm{~min}$ at $4{ }^{\circ} \mathrm{C}$. The supernatant was used as fibrin-depleted plasma in cell culture [25]. After several washing steps, PBMCs were resuspended in Roswell Park Memorial Institute (RPMI) 1640 medium and seeded into $75-\mathrm{cm}^{2}$ flasks at $5 \times 10^{7}$ cells $/ \mathrm{ml}$. After $2 \mathrm{~h}$ of incubation at $37^{\circ} \mathrm{C}$ and $5 \% \mathrm{CO}_{2}$, non-adherent cells were removed by gentle pipette aspiration. Adherent cells (monocytes) were detached using ice-cold phosphate-buffered saline (PBS), washed and resuspended in RPMI 1640 medium containing 2 $\mathrm{mmol} / \mathrm{l}$ glutamine, $1 \%$ sodium pyruvate, $1 \%$ nonessential amino acids, $1 \%$ penicillin/streptomycin (pen-strep), and 10\% autologous fibrin-depleted plasma. Monocytes were cultured in RPMI 1640 supplemented as above for 3 days in the presence of $100 \mathrm{ng} / \mathrm{ml}$ recombinant macrophage colony-stimulating factor (M-CSF, r; Peprotech, Rocky Hill, NJ, USA), then for 3 more days in the presence of $100 \mathrm{ng} / \mathrm{ml}$ M-CSF, $1 \mu \mathrm{mol} / \mathrm{l}$ recombinant CXCL4 (PF4) (Peprotech), 1 $\mathrm{U} / \mathrm{ml}$ FVIII, or supernatant from FVIII-treated human platelets.

\section{Hemoglobin-Induced Cell Stress}

Macrophage responses to hemoglobin were assessed according to Gleissner et al. [19] with some modifications. Briefly, macrophages were cultured for 6 days as described above. At the time of PBMC isolation from buffy coats, red 

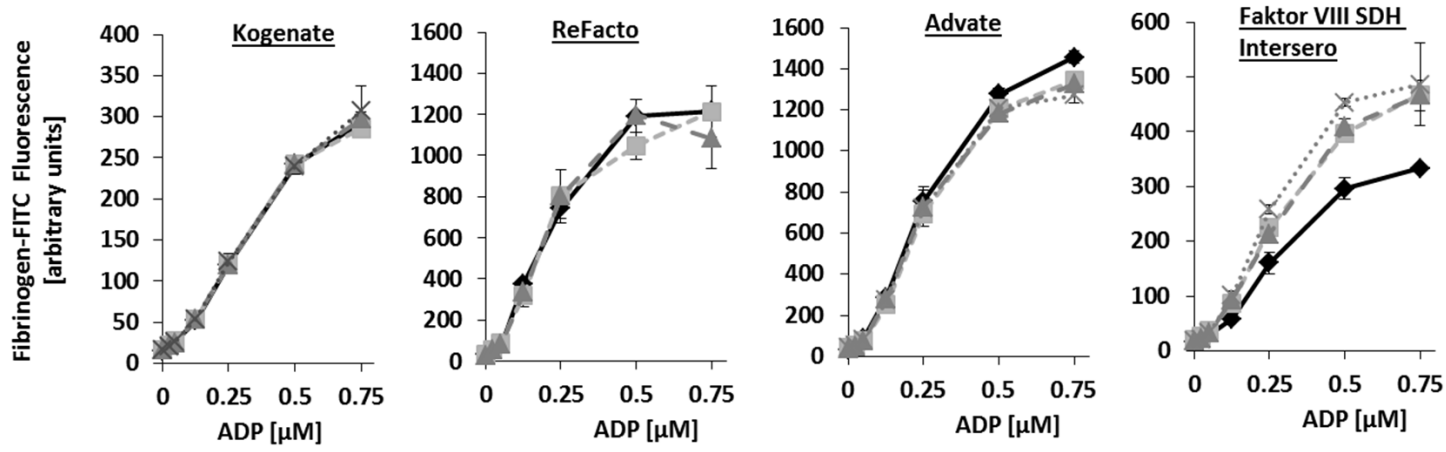

Fig. 1. Some plasmaderived factor VIII products augment agonist-induced platelet fibrinogen binding. Platelets were incubated with $0.5-2 \mathrm{U} / \mathrm{ml}$ of the indicated factor VIII product and $3 \mu \mathrm{mol} / \mathrm{l}$ melagatran for $1 \mathrm{~h}$ and then activated with $\mathrm{ADP}$ for 5 $\min$ in the presence of fibrinogen-FITC. After fixation, cells were washed and analyzed by flow cytometry. Data show mean \pm standard deviation (SD) from 3 independent experiments. ADP $=$ adenosine diphosphate; FITC $=$ fluorescein isothiocyanate.
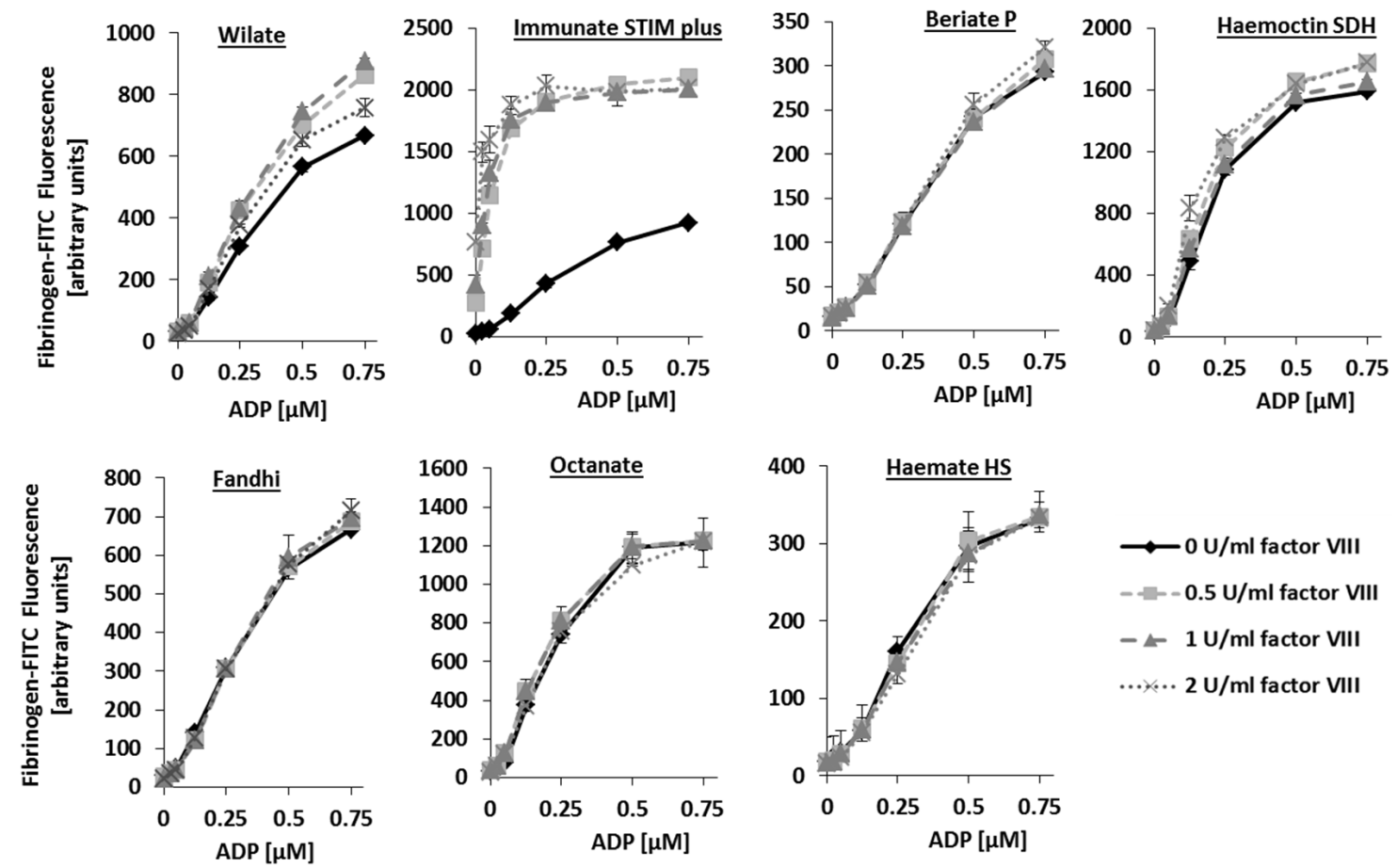

blood cell lysates and fibrin-depleted plasma were kept and stored at $-20{ }^{\circ} \mathrm{C}$. On day 6 after PBMC isolation, macrophages were incubated with RPMI 1640 medium supplemented as above and also containing $0.5 \mathrm{mg} / \mathrm{ml}$ autologous hemoglobin from red blood cell lysate. After $18 \mathrm{~h}$, cells were harvested, and HO-1 protein expression was measured by flow cytometry.

\section{CXCL4 ELISA}

CXCL4 in platelet supernatant was measured by enzyme-linked immunosorbent assay (ELISA; Asserachrom PF4, Diagnostica Stago, Asnieres-SurSeine, France) as instructed by the manufacturer.

\section{Flow Cytometry}

\section{Characterization of Platelets}

Platelet activation was assessed as described previously [26]. Briefly, plateletrich plasma diluted in 4-[2-hydroxyethyl]-1-piperazineethanesulfonic acid(HEPES)-buffered Tyrode solution ( $\mathrm{pH} 7.4$ ) to a concentration of $2.5 \times 10^{7}$ platelets $/ \mathrm{ml}$ was incubated with FVIII $(0.5-2 \mathrm{U} / \mathrm{ml})$ in the presence of $0.5 \mu \mathrm{mol} / \mathrm{l}$ $\mathrm{CaCl}_{2}$ and $3 \mu \mathrm{mol} / \mathrm{l}$ melagatran (to prevent secondary platelet activation by thrombin) for $1 \mathrm{~h}$ at room temperature. Afterward, platelets were activated with ADP $(0.025-0.75 \mu \mathrm{mol} / \mathrm{l})$ or ADP plus U46619 $(0.5 \mu \mathrm{mol} / \mathrm{l})$ for $5 \mathrm{~min}$. For analysis of platelet fibrinogen binding, platelet activation was performed in the pres- ence of $150 \mu \mathrm{g} / \mathrm{ml}$ fibrinogen-FITC. Platelets were then fixed with $0.5 \%$ formaldehyde and washed. For CD62P expression, platelets were incubated with predefined saturating concentrations of the monoclonal antibody anti-CD62P-FITC (Becton Dickinson, Heidelberg, Germany). Finally, samples were analyzed by fluorescence-activated cell scanning (FACS Calibur; Becton Dickinson) as described previously [27]. A total of 5,000 events were analyzed for each data point.

Characterization of Macrophages

For detachment of macrophages, cells were incubated with ice-cold PBS containing $2.5 \mathrm{mmol} / \mathrm{l}$ ethylenediaminetetraacetic acid (EDTA) on ice for $15 \mathrm{~min}$. Macrophages were incubated with previously defined saturating concentrations of monoclonal anti-CD163-PE (clone GHI/61; Becton Dickinson) or isotype control for $15 \mathrm{~min}$ at $4{ }^{\circ} \mathrm{C}$. For intracellular staining of HO-1, cells were fixed with $2 \%$ formaldehyde in PBS, permeabilized with $0.1 \%$ saponin (Sigma Aldrich) and $0.5 \%$ bovine serum albumin (Calbiochem, San Diego, CA, USA) in PBS and subsequently stained with predefined saturating concentrations of anti-HO-1-PE (clone HO-1-2; Enzo Life Sciences, Lörrach, Germany). Samples were analyzed by fluorescence-activated cell scanning (FACS Calibur; Becton Dickinson).

\section{Statistics}

The results are expressed as mean \pm standard deviation. Statistical significance was determined using the unpaired Student $\mathrm{t}$ test. $\mathrm{P}$ values $<0.05$ were regarded as significant. 

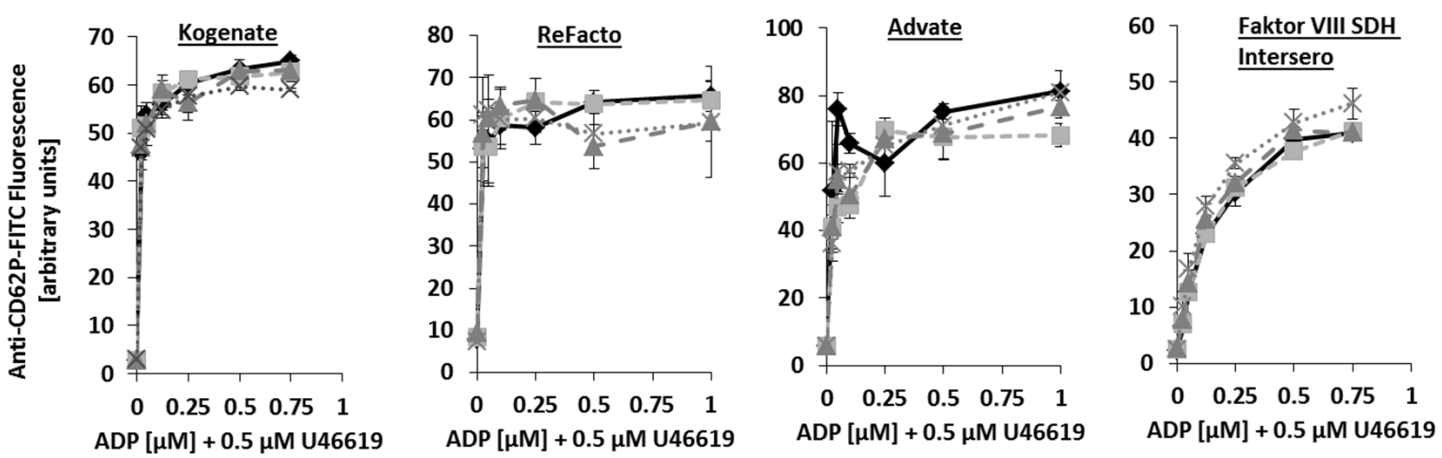

Fig. 2. Some plasmaderived factor VIII products augment agonist-induced platelet CD62P expression. Platelets were incubated with $0.5-2 \mathrm{U} / \mathrm{ml}$ of the indicated factor VIII product and 3 $\mu \mathrm{mol} / \mathrm{l}$ melagatran for $1 \mathrm{~h}$ and then activated with ADP plus U46619 for $5 \mathrm{~min}$. After fixation, cells were stained with anti-CD62PFITC, washed and analyzed by flow cytometry. Data show mean \pm standard deviation (SD) from 3 independent experiments. ADP $=$ adenosine diphosphate; FITC $=$ fluores cein isothiocyanate.

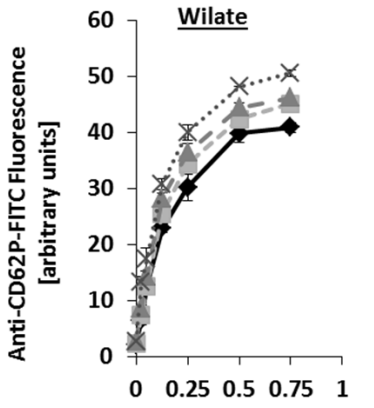

$\mathrm{ADP}[\mu \mathrm{M}]+0.5 \mu \mathrm{M} U 46619$

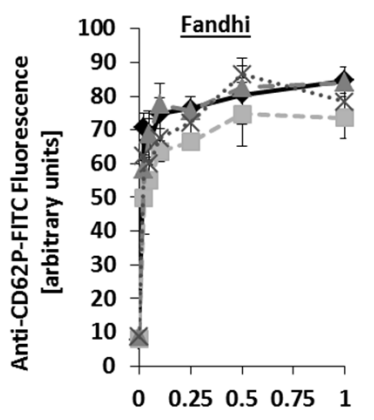

$\mathrm{ADP}[\mu \mathrm{M}]+0.5 \mu \mathrm{M} \mathrm{U} 46619$
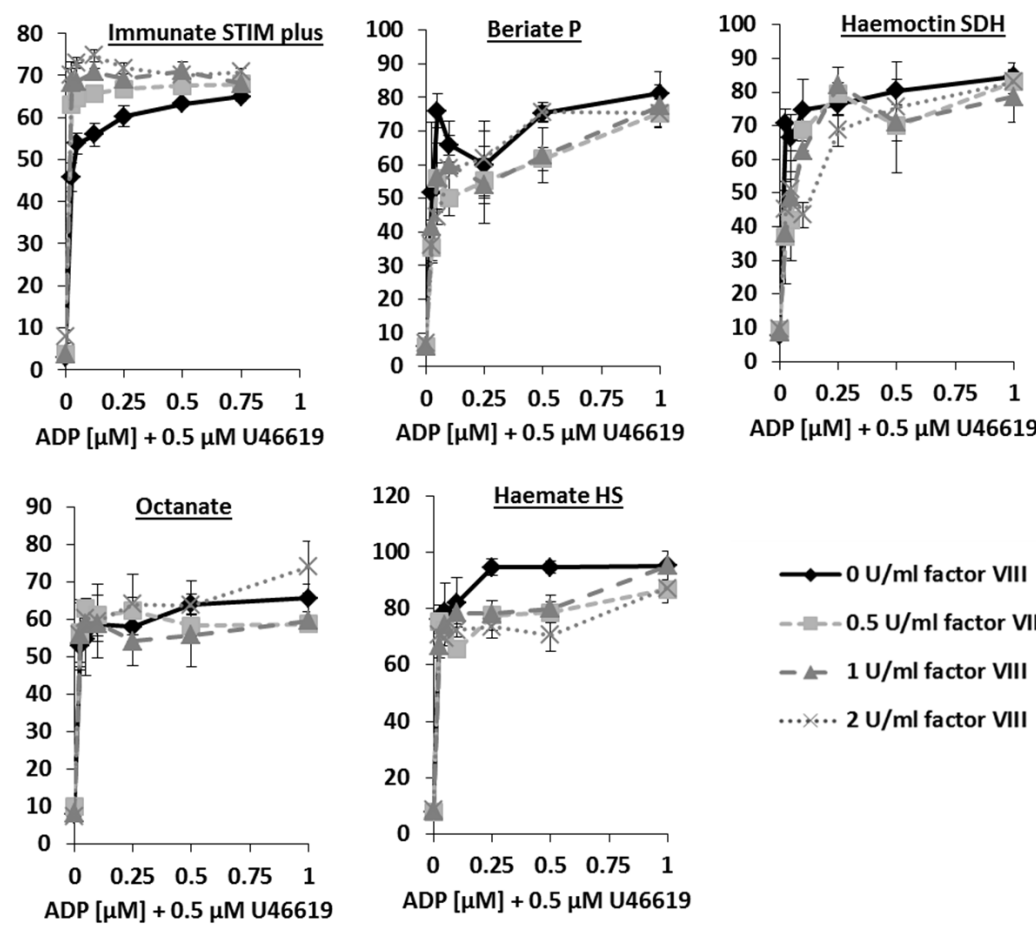

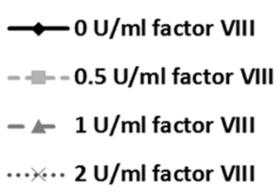

\section{Results}

\section{Several Plasma-Derived FVIII Products Augment Platelet Activation}

As we reported earlier, several plasma-derived FVIII products contain substances that influence platelet activation status and/or inflammation that were absent in recombinant FVIII [21]. Among them was alpha-defensin, a neutrophil cationic peptide, which besides exerting antimicrobial and proinflammatory functions, acts as a potent platelet agonist [20]. Therefore, we tested the effect of plasma-derived and recombinant FVIII concentrates on platelet activation. All three tested recombinant FVIII products (Kogenate Bayer, ReFacto AF, and Advate) had no effect on ADP-induced platelet fibrinogen binding. In contrast, three of the plasma-derived FVIII products (Immunate STIM plus, Faktor VIII SDH Intersero, and Wilate) significantly enhanced fibrinogen binding to ADP-stimulated platelets, with the strongest effect observed with Immunate STIM plus, which also activated platelets in the absence of ADP (fig. 1). The same three plasma-derived products also increased ADP plus U46619-induced CD62P expression on the platelet surface in a concentration-dependent manner (fig. 2).
Again, the three tested recombinant products had no such effect. Interestingly, all eight tested plasma-derived FVIII products induced significant CXCL4 release from platelets. In contrast, none of the 3 tested recombinant products prompted platelet CXCL4 release (fig. 3).

\section{Supernatant of Platelets Treated with Plasma-Derived FVIII}

Products Promotes the Formation of M4 Macrophages That Are Unable to Deal with Hemoglobin Stress

Gleissner et al. [19] showed that CXCL4 decreases the expression of the protective hemoglobin scavenger receptor CD163 on human monocytes. As some plasma-derived FVIII concentrates contain up to $0.85 \mathrm{ng} / \mathrm{IU}$ of the platelet alpha granule protein CXCL4 [21], and all tested plasma-derived products induced significant CXCL4 release from human platelets (fig. 3), we tested the effect of FVIII concentrates and supernatant from FVIII-treated platelets on macrophage CD163 expression. Human monocytes were cultured for 3 days with M-CSF and for an additional 3 days with M-CSF \pm CXCL4, FVIII concentrates, or supernatant from platelets (untreated or exposed to either FVIII concentrates or ADP plus U46619). Although some of the tested plasma-derived 
FVIII products contain low concentrations of CXCL4 [21], none affected CD163 expression on human macrophages directly (data not shown), whereas CXCL4 downregulated CD163 as previously described [19]. In contrast, supernatant of platelets treated with plasma-derived FVIII diminished macrophage CD163 surface ex-

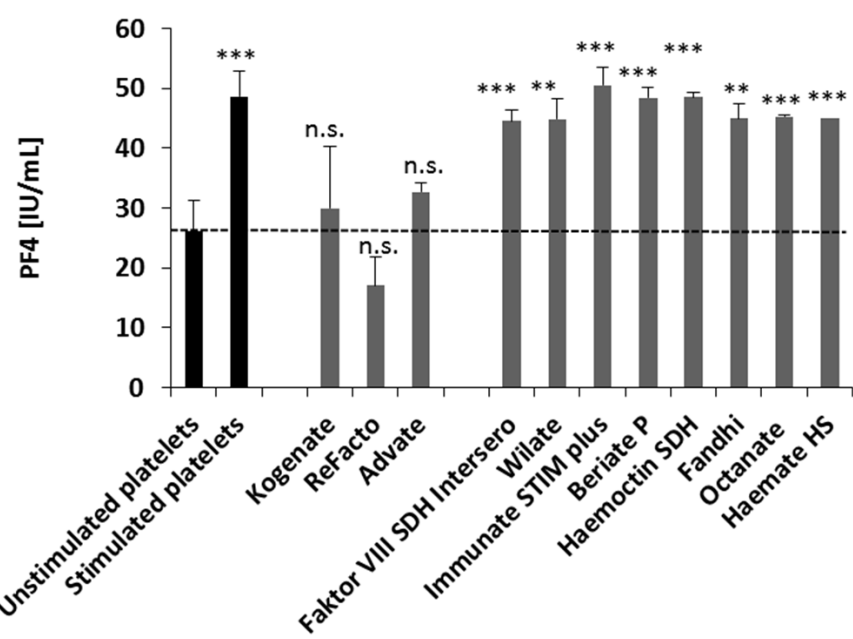

Fig. 3. Plasma-derived factor VIII products, but not recombinant factor VIII, induce release of CXCL4 by human platelets. Gel-filtered human platelets were incubated with $2 \mathrm{U} / \mathrm{ml}$ of the indicated factor VIII product and $3 \mu \mathrm{mol} / \mathrm{l}$ melagatran for 1 hour, pelleted and supernatant was analyzed regarding platelet factor 4 concentration using ELISA. Supernatant from unstimulated platelets served as negative control and supernatant from platelets stimulated with $1 \mu \mathrm{mol} / \mathrm{l}$ ADP plus $0.5 \mu \mathrm{l} \mathrm{U} 46619$ was used as positive control. Data are mean \pm standard deviation (SD) from 3 independent experiments. ${ }^{* *} \mathrm{p}<0.005 ;{ }^{* *} \mathrm{p}<$ 0.01. $\mathrm{ADP}=$ adenosine diphosphate; ELISA = enzyme-linked immunosorbent assay; n.s. = not significant. pression to the same extent as $1 \mu \mathrm{mol} / \mathrm{l}$ recombinant CXCL4 or supernatant of ADP plus U46619-stimulated platelets, whereas supernatant of untreated platelets and platelets treated with recombinant FVIII had no effect (fig. 4).

Because CD163-negative M4-macrophages are unable to upregulate HO-1 in response to hemoglobin stress [19], we investigated whether macrophages that differentiated from monocytes in the presence of supernatant from FVIII-treated platelets were able to raise $\mathrm{HO}-1$ protein expression in response to hemoglobin. Therefore, we treated macrophages that were grown in the presence of M-CSF, CXCL4, or supernatant from platelets (untreated platelets or platelets treated with FVIII products or ADP plus U46619, as described above) with autologous hemoglobin and autologous fibrin-depleted plasma for $18 \mathrm{~h}$, in order to ensure sufficient amounts of haptoglobin. Cells were then analyzed for HO-1 expression by flow cytometry. As shown in figure 5, macrophages that were grown in the presence of CXCL4 or supernatant from platelets treated with plasma-derived FVIII or ADP plus U46619 exhibited significantly lower HO-1 expression levels than macrophages that were grown in the presence of M-CSF alone or with supernatant from untreated platelets or platelets treated with recombinant FVIII.

\section{Discussion}

Joint bleeding and debilitating arthropathy still occur in patients with severe hemophilia in spite of early prophylaxis [2]. The reason for this is unknown. Recently, Gleissner et al. [19] found that the platelet alpha granule protein CXCL4 promotes differenti-
Fig. 4. Supernatant of platelets treated with plasma-derived factor VIII products downregulates CD163 expression on human macrophages. Human monocytes were cultured to macrophages in the presence of M-CSF for 3 days then for 3 days with M-CSF \pm CXCL4 or supernatant from untreated platelets or platelets, treated with different factor VIII products or ADP plus U46619, as indicated. Cells were harvested, stained with anti-CD163-PE and analyzed by flow cytometry. Data show mean \pm standard deviation (SD) from 3 independent experiments. ${ }^{* *} \mathrm{p}<0.005 ;{ }^{* *} \mathrm{p}<0.01$; ${ }^{*} \mathrm{p}<0.05 . \mathrm{ADP}=$ adenosine diphosphate; $\mathrm{M}-\mathrm{CSF}=$ macrophage colony-stimulating factor; n.s. $=$ not significant; $\mathrm{PE}=$ phycoerythrin; $\mathrm{PF} 4=$ platelet factor 4 (CXCL4).

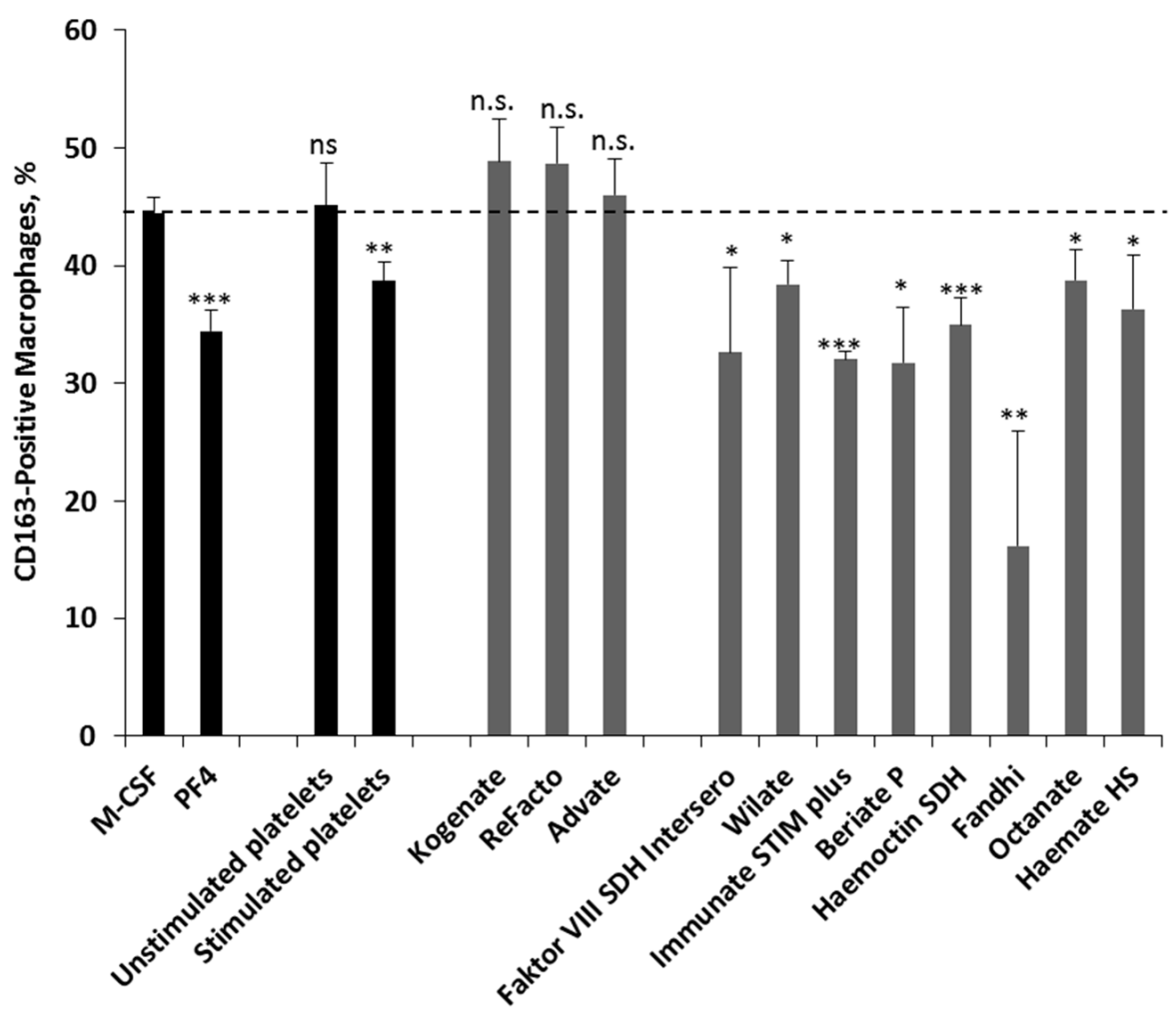

Transfus Med Hemother 2017;44:351-357 
Fig. 5. Supernatant of platelets treated with plasma-derived factor VIII products promote the formation of macrophages that are unable to upregulate $\mathrm{HO}-1$ in response to hemoglobin. Human monocytes were cultured to macrophages in the presence of M-CSF for 3 days then for 3 days with M-CSF \pm CXCL4 or supernatant from untreated platelets or platelets treated with different factor VIII products or with ADP plus U46619, as indicated. Cells were then incubated with autologous hemoglobin for $18 \mathrm{~h}$, harvested, permeabilized and stained with anti-HO-1-PE prior to analysis by flow cytometry. Data show mean \pm standard deviation (SD) from 3 independent experiments. ${ }^{* * *} \mathrm{p}<0.005 ;{ }^{* *} \mathrm{p}<0.01 ;{ }^{*} \mathrm{p}<0.05$. ADP $=$ adenosine diphosphate; HO-1 = heme oxygenase 1 ; $\mathrm{M}-\mathrm{CSF}=$ macrophage colony-stimulating factor; n.s. $=$ not significant $; \mathrm{PE}=$ phycoerythrin; $\mathrm{PF} 4=$ platelet factor 4 (CXCL4).

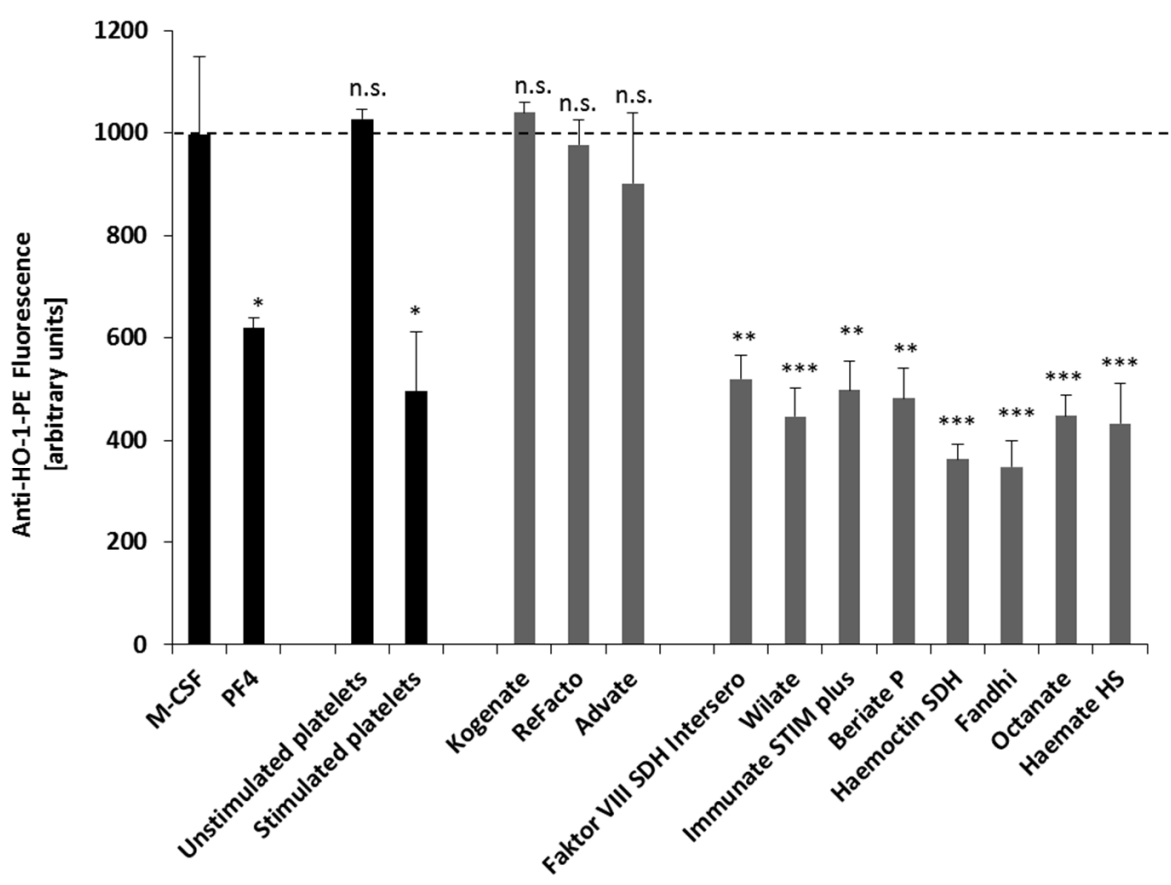

ation of CD163-negative M4-type macrophages that are unable to ingest free hemoglobin and to upregulate the protective enzyme HO-1. In this study, we report that in contrast to recombinant FVIII, components of plasma-derived FVIII concentrates induce significant CXCL4 release from human platelets. In addition, three of the eight tested plasma-derived products (Immunate STIM plus, Wilate, and Faktor VIII SDH Intersero) augmented ADP-induced binding of fibrinogen to platelets. In contrast, the three tested recombinant FVIII products (Kogenate, ReFacto AF, and Advate) and five of the eight plasma-derived products (Octanate, Fandhi, Haemoctin SDH, Haemeate HS, and Beriate P) had no effect on platelet fibrinogen binding. The direct assay using fibrinogen conjugated with FITC in a 1:6 ratio has been well established in the study group $[23,28]$. The high coupling rate provides suitable fluorescence signals even in the presence of plasma. The same three plasma-derived FVIII concentrates that enhanced fibrinogen binding (Immunate STIM plus, Wilate, and Faktor VIII SDH Intersero) also augmented ADP plus U46619(thromboxane analogue)-induced platelet CD62P (P-selectin) expression. Again, the three recombinant FVIII products and the five other tested plasma-derived products had no significant effect that could be measured by flow cytometry. The divergence between the findings in CD62P expression and CXCL4 expression that was induced by all of the eight tested plasma-derived FVIII products, even in the absence of ADP, might result from differences in the sensitivity of the methods used (flow cytometry vs. ELISA). The platelet-activating activity of the products might rely on impurities such as alpha-defensin that we found in several plasma-derived FVIII concentrates previously [21]. As reported earlier, alpha-defensin acts as a potent platelet agonist, inducing platelet fibrinogen binding and degranulation [20]. Importantly, supernatant of platelets treated with plasma-derived FVIII products significantly downregulated CD163 on the surface of human macrophages. Therefore, the CD163 expression was comparable with that of macrophages treated with $1 \mu \mathrm{mol} / \mathrm{l}$ recombinant CXCL4 $(\approx 29 \mu \mathrm{g} / \mathrm{ml})$ or supernatant from ADP plus U46619-treated platelets. Although some plasma-derived FVIII concentrates contain up to $0.85 \mathrm{ng} /$ IU of CXCL4 [20], we were not able to detect a direct effect of these products on macrophage CD163 expression. Importantly, similar to the macrophages grown in the presence of $1 \mu \mathrm{mol} / \mathrm{l} \mathrm{CXCL4}$, the macrophages that were grown in the presence of supernatant from plasma-derived FVIII treated platelets were unable to increase $\mathrm{HO}-1$ expression after incubation with hemoglobin.

When joint bleeds occur in hemophilic patients, erythrocytes are lysed, releasing hemoglobin. Simultaneously, platelets arrive in the joint space. The proinflammatory effects of hemoglobin/iron are of central importance for the pathophysiology of joint destruction in hemophilia. For example, iron induces the expression of the 2 proto-oncogenes, c-MYC and MDM-2, causing synovial proliferation and inhibition of apoptosis [6-8]. Furthermore, iron deposits in synovial tissue are associated with increased synthesis of proinflammatory cytokines that enhance the catabolic activity of cartilage chondrocytes resulting in cartilage damage [4]. Iron-catalyzed generation of hydroxyl radicals results in apoptosis of joint cells [29]. Recently, Nieuwenhuizen et al. [30] reported that the iron-chelating agent deferasirox significantly reduced cartilage damage in hemophilic mice, demonstrating the central role of iron in joint disease. Our in vitro data suggest that patients who receive plasma-derived FVIII products might have a disadvantage in the handling of rising oxidative stress. Platelets in combination with these concentrates might result in high local CXCL4 levels in the affected joints. The outcome of this might be CD163-negative M4macrophages that have an impaired ability to bind and ingest hemoglobin-haptoglobin complexes and fail to upregulate the joint-protective enzyme HO-1 in response to free hemoglobin. This scenario might explain why some patients with severe hemo- 
philia develop arthropathy in spite of early prophylaxis [2]. Although FVIII concentrates are highly diluted upon administration, sufficient levels are evidently achieved in the vicinity of platelets to induce clotting. The local concentrations of active compounds that actually occur in the synovial fluid can ethically not be determined in patients, but these will conceivably be higher the larger the wound and the higher the amount of concentrate administered. It is therefore feasible that the effects observed here in vitro will also be of relevance in the clinical setting. Whether the reported in vitro effect also occurs in vivo must be the matter of further investigation.

\section{Acknowledgements}

This work was supported by a grant from Bayer Vital GmbH, Leverkusen, Germany, and travelling support to present parts of the work at two scientific congresses. Editorial assistance in proof-reading the English language was done by Complete Healthcare Communications, Inc. (Chadds Ford, PA, USA) and was funded by Bayer HealthCare.

\section{Disclosure Statement}

The authors have no conflicting financial interests.

\section{References}

1 Roosendaal G, Lafeber FP: Blood-induced joint damage in hemophilia. Semin Thromb Hemost 2003;29: $37-42$.

2 Olivieri M, Kurnik K, Pfluger T, Bidlingmaier C: Identification and long-term observation of early join damage by magnetic resonance imaging in clinically asymptomatic joints in patients with haemophilia $\mathrm{A}$ or B despite prophylaxis. Haemophilia 2012;18:369-374.

$\checkmark 3$ Andersen CB, Torvund-Jensen M, Nielsen MJ, de Oliveira CL, Hersleth HP, Andersen NH, Pedersen JS, Andersen GR, Moestrup SK: Structure of the haptoglobinhaemoglobin complex. Nature 2012;489:456-459.

4 Roosendaal G, Vianen ME, Wenting MJ, van Rinsum AC, van den Berg HM, Lafeber FP, Bijlsma JW: Iron deposits and catabolic properties of synovial tissue from patients with haemophilia. J Bone Joint Surg 1998;80:540-545.

5 Valentino LA, Hakobyan N, Enockson C, Simpson ML, Kakodkar NC, Cong L, Song X: Exploring the biological basis of haemophilic joint disease: experimental studies. Haemophilia 2012;18:310-318.

6 Nishiya K: Stimulation of human synovial cell DNA synthesis by iron. J Rheumatol 1994;21:1802-1807.

7 Hakobyan N, Kazarian T, Jabbar AA, Jabbar KJ, Valentino LA: Pathobiology of hemophilic synovitis I: overexpression of mdm2 oncogene. Blood 2004;104: 2060-2064.

$\checkmark 8$ Wen FQ, Jabbar AA, Chen YX, Kazarian T, Patel DA, Valentino LA: c-myc proto-oncogene expression in hemophilic synovitis: in vitro studies of the effects of iron and ceramide. Blood 2002;100:912-916.

9 Buehler PW, Abraham B, Vallelian F, Linnemayr C, Pereira CP, Cipollo JF, Jia Y, Mikolajczyk M, Boretti FS, Schoedon G, Alayash AI, Schaer DJ: Haptoglobin preserves the CD163 hemoglobin scavenger pathway by shielding hemoglobin from peroxidative modification. Blood 2009;113:2578-2586.

10 Lim SK, Kim H, bin Ali A, Lim YK, Wang Y, Chong SM, Costantini F, Baumman H: Increased susceptibility in $\mathrm{Hp}$ knockout mice during acute hemolysis. Blood 1998;92:1870-1877.
Kristiansen M, Graversen JH, Jacobsen C, Sonne O, Hoffman HJ, Law SK, Moestrup SK: Identification of the haemoglobin scavenger receptor. Nature 2001;409: 198-201.

12 Schaer CA, Schoedon G, Imhof A, Kurrer MO, Schaer DJ: Constitutive endocytosis of CD163 mediates hemoglobin-heme uptake and determines the noninflammatory and protective transcriptional response of macrophages to hemoglobin. Circ Res 2006;99:943-950.

13 de Waal Malefyt R, Abrams J, Bennett B, Figdor CG, de Vries JE: Interleukin 10(IL-10) inhibits cytokine synthesis by human monocytes: an autoregulatory role of IL-10 produced by monocytes. J Exp Med 1991;174: 1209-1220.

14 Philippidis P, Mason JC, Evans BJ, Nadra I, Taylor KM, Haskard DO, Landis RC: Hemoglobin scavenger receptor CD163 mediates interleukin-10 release and heme oxygenase- 1 synthesis: antiinflammatory monocyte-macrophage responses in vitro, in resolving skin blisters in vivo, and after cardiopulmonary bypass surgery. Circ Res 2004;94:119-126.

15 Nath KA: Heme oxygenase-1:a provenance for cytoprotective pathways in the kidney and other tissues. Kidney Int 2006;70:432-443.

16 Gordon S, Taylor PR: Monocyte and macrophage heterogeneity. Nat Rev Immunol 2005;5:953-964.

17 Scheuerer B, Ernst M, Durrbaum-Landmann I, Fleischer J, Grage-Griebenow E, Brandt E, Flad HD, Petersen $\mathrm{F}$ : The CXC-chemokine platelet factor 4 promotes monocyte survival and induces monocyte differentiation into macrophages. Blood 2000;95:1158-1166.

18 Gleissner CA: Macrophage phenotype modulation by CXCL4 in atherosclerosis. Front Physiol 2012;3:1.

19 Gleissner CA, Shaked I, Erbel C, Bockler D, Katus HA, Ley K: CXCL4 downregulates the atheroprotective hemoglobin receptor CD163 in human macrophages. Circul Res 2010;106:203-211.

20 Horn M, Bertling A, Brodde MF, Muller A, Roth J, Van Aken H, Jurk K, Heilmann C, Peters G, Kehrel BE: Human neutrophil alpha-defensins induce formation of fibrinogen and thrombospondin-1 amyloid-like structures and activate platelets via glycoprotein IIb/ IIIa. J Thromb Haemost 2012;10:647-661.
21 Brodde MF, Kehrel BE: Markers of blood cell activation and complement activation in factor VIII and von Willebrand factor concentrates. Transfus Med Hemother 2010;37:175-184.

22 Xia Z, Wong T, Liu Q, Kasirer-Friede A, Brown E, Frojmovic MM: Optimally functional fluorescein isothiocyanate-labelled fibrinogen for quantitative studies of binding to activated platelets and platelet aggregation. Br J Haematol 1996;93:204-214.

23 Lahav J, Jurk K, Hess O, Barnes MJ, Farndale RW, Luboshitz J, Kehrel BE: Sustained integrin ligation involves extracellular free sulfhydryls and enzymatically catalyzed disulfide exchange. Blood 2002;100:24722478

24 Dormann D, Clemetson KJ, Kehrel BE: The GPIb thrombin-binding site is essential for thrombin-induced platelet procoagulant activity. Blood 2000;96: 2469-2478.

25 Davies JQ, Gordon S: Isolation and culture of human macrophages. Methods Mol Biol 2005;290:105-116.

26 Bertling A, Niemann S, Uekotter A, Fegeler W, LassFlorl C, von Eiff C, Kehrel BE: Candida albicans and its metabolite gliotoxin inhibit platelet function via interaction with thiols. Thromb Haemost 2010;104:270-278.

27 Dormann D, Kardoeus J, Zimmermann RE, Kehrel B: Flow cytometric analysis of agonist-induced annexin $\mathrm{V}$, factor Va and factor Xa binding to human platelets. Platelets 1998;9:171-177.

28 Niemann S, Spehr N, Van Aken H, Morgenstern E, Peters G, Herrmann M, Kehrel BE: Soluble fibrin is the main mediator of Staphylococcus aureus adhesion to platelets. Circulation 2004;110:193-200.

29 Roosendaal G, Vianen ME, van den Berg HM, Lafeber FP, Bijlsma JW: Cartilage damage as a result of hemarthrosis in a human in vitro model. The Journal of rheumatology 1997;24:1350-1354.

-30 Nieuwenhuizen L, Roosendaal G, Mastbergen SC Coeleveld K, Biesma DH, Lafeber FP, Schutgens RE: Deferasirox limits cartilage damage following haemarthrosis in haemophilic mice. Thromb Haemost 2014; 112:1044-1050 